\title{
Genome-wide association studies for tick resistance in Bos taurus $\times$ Bos indicus crossbred cattle: A deeper look into this intricate mechanism
}

\author{
Pamela I. Otto, ${ }^{*}$ Simone E. F. Guimarães, ${ }^{*}$ Lucas L. Verardo, ${ }^{*}$ Ana Luísa S. Azevedo, $†$ Jeremie Vandenplas,‡ \\ Aline C. C. Soares, ${ }^{*}$ Claudia A. Sevillano, $\neq \S$ Renata Veroneze, ${ }^{*}$ Maria de Fatima A. Pires, $\dagger$ \\ Célio de Freitas, $\dagger$ Márcia Cristina A. Prata, $\uparrow$ John Furlong, $\dagger$ Rui S. Verneque, $\dagger$ Marta Fonseca Martins, $\dagger$ \\ João Cláudio C. Panetto, † Wanessa A. Carvalho, † Diego O. R. Gobo, * \\ Marcos Vinícius G. B. da Silva, $†$ and Marco A. Machado ${ }^{1}$ \\ *Department of Animal Science, Universidade Federal de Viçosa, Viçosa, MG, 36570-977 Brazil \\ †EMBRAPA, Dairy Cattle Research Center, Juiz de Fora, MG, 36038-330 Brazil \\ $\ddagger$ Wageningen University \& Research Animal Breeding and Genomics, $6700 \mathrm{AH}$ Wageningen, the Netherlands \\ $\S$ Topigs Norsvin Research Center, 6640 AA Beuningen, the Netherlands
}

\begin{abstract}
Rhipicephalus (Boophilus) microplus is the main cattle ectoparasite in tropical areas. Gir $\times$ Holstein crossbred cows are well adapted to different production systems in Brazil. In this context, we performed genome-wide association study (GWAS) and post-GWAS analyses for $R$. microplus resistance in an experimental Gir $\times$ Holstein $\mathrm{F}_{2}$ population. Single nucleotide polymorphisms (SNP) identified in GWAS were used to build gene networks and to investigate the breed of origin for its alleles. Tick artificial infestations were performed during the dry and rainy seasons. Illumina BovineSNP50 BeadChip (Illumina Inc., San Diego, CA) and single-step BLUP procedure was used for GWAS. Post-GWAS analyses were performed by gene ontology terms enrichment and gene transcription factors networks, generated from enriched transcription factors, identified from the promoter sequences of selected gene sets. The genetic origin of marker alleles in the $\mathrm{F}_{2}$ population was assigned using the breed of origin of alleles approach. Heritability estimates for tick counts were $0.40 \pm 0.11$ in the rainy season and $0.54 \pm 0.11$ in the dry season. The top ten $0.5-\mathrm{Mbp}$ windows with the highest percentage of genetic variance explained by SNP markers were found in chromosomes 10 and 23 for both the dry and rainy seasons. Gene network analyses allowed the identification of genes involved with biological processes relevant to immune system functions (TREM1, TREM2, and CD83). Gene-transcription factors network allowed the identification of genes involved with immune functions (MYO5A, TREML1, and PRSS16). In resistant animals, the average proportion of animals
\end{abstract}

Received November 30, 2017.

Accepted May 29, 2018.

${ }^{1}$ Corresponding author: marco.machado@embrapa.br showing significant SNPs with paternal and maternal alleles originated from Gir breed was $44.8 \%$ whereas the proportion of animals with both paternal and maternal alleles originated from Holstein breed was $11.3 \%$. Susceptible animals showing both paternal and maternal alleles originated from Holstein breed represented $44.6 \%$ on average, whereas both paternal and maternal alleles originated from Gir breed animals represented $9.3 \%$. This study allowed us to identify candidate genes for tick resistance in Gir $\times$ Holstein crossbreds in both rainy and dry seasons. According to the origin of alleles analysis, we found that most animals classified as resistant showed 2 alleles from Gir breed, while the susceptible ones showed alleles from Holstein. Based on these results, the identified genes may be thoroughly investigated in additional experiments aiming to validate their effects on tick resistance phenotype in cattle. Key words: breed of origin, gene network, genetic variance, Gir $\times$ Holstein crossbred

\section{INTRODUCTION}

Among the parasites that affect cattle, ticks are the main cause of economic losses in tropical and subtropical regions around the world (Molento et al., 2013). The bovine tick, Rhipicephalus (Boophilus) microplus, promotes several losses in bovine production due to weight loss, behavioral changes, secondary skin infections, and transmission of viral, bacterial, and protozoa pathogens that can be fatal to the host (Léger et al., 2013).

Breeds of Bos indicus are genetically more resistant to ticks than Bos taurus due the presence of naturally selected genes throughout their evolutionary process (Ibelli et al., 2012; Ayres et al., 2015). Genetic variability for bovine tick resistance has been reported (Cardoso et al., 2014), showing potential for the improvement 
of this trait. According to Walker (2011), individual ability of cattle to acquire tick immunity is hereditary. In that work, European animals showed moderate immunological capacity (approximately $85 \%$ of the larvae died due to the animal's immune defense), whereas Bos indicus cattle exhibited high immune defense capacity (98\% of dead larvae).

Rhipicephalus microplus tick is considered the main ectoparasite affecting cattle production in Brazil, showing high prevalence in tropical and subtropical regions (Shyma et al., 2015). Due to its large climatic diversity, the search for animals adapted to the different Brazilian regions is very important for the success of milk production. In this sense, Gir cattle (Bos indicus), a breed which is resistant to hot temperatures and tropical diseases, are crossed with Holstein cattle (Bos taurus), to generate the Girolando. Girolando is a synthetic breed that is $5 / 8$ Holstein and $3 / 8$ Gir by definition. This breed has shown a great adaptation throughout Brazil and accounts for $80 \%$ of the milk produced in the country (Ferro et al., 2010). The evaluation of adaptive traits is of great importance to livestock production systems because it allows the identification of the most tolerant animals to biotic and abiotic stress conditions. Subsequently, these traits can be used as selection criteria in breeding programs.

Genome-wide association studies (GWAS) have been performed to identify genomic regions associated with resistance to bovine ticks (Gasparin et al., 2007; Machado et al., 2010; Porto Neto et al., 2011). Nevertheless, information about genes underlying this trait and their breed of origin are still scarce. Post-GWAS analyses, including gene networks and gene ontology enrichment analyses, as well as the identification of relevant transcription factors can contribute to a better understanding of the molecular mechanisms involved in the complex pathogen-host interaction during $R$. microplus infestation in cattle. The identification of the origin of alleles in crossbred animals (Sevillano et al., 2016; Vandenplas et al., 2016) is also important in this context.

Thus, we aimed to perform GWAS and post-GWAS analyses for $R$. microplus resistance in cattle, using an experimental Gir $\times$ Holstein $\mathrm{F}_{2}$ population. We identified SNP in GWAS to build gene networks and to investigate the breed of origin for its alleles.

\section{MATERIALS AND METHODS}

\section{Experimental Population and Phenotypic Data}

Data were obtained from Embrapa Dairy Cattle Research Center, located in southeastern Brazil. An experimental population was generated and evaluated for $R$. microplus resistance as described by Machado et al. (2010). Tick artificial infestations were performed in each $\mathrm{F}_{2}$ animal during the dry (April to September) and rainy (October to March) seasons, from 2001 to 2007. After $21 \mathrm{~d}$ of infestation, the number of ticks was measured in each $\mathrm{F}_{2}$ animal. Animals were evaluated in contemporary groups aged between 10 and 14 mo. Additional traits that might affect the tick resistance evaluations were also assessed, including coat color, coat thickness, and length, density, and type of hair.

\section{DNA Extraction and SNP Genotyping}

Blood samples from parental, $\mathrm{F}_{1}$, and $\mathrm{F}_{2}$ populations were collected using vacuum tubes containing anticoagulant. The DNA was extracted from white blood cells using a modified phenol/chloroform method (Machado et al., 2010). Quality and concentration of DNA were determined by NanoDrop 1000 spectrophotometer (Thermo Scientific, Waltham, MA). Subsequently, all samples were genotyped with the Illumina BovineSNP50 BeadChip (Illumina Inc., San Diego, CA).

Genotype quality control was implemented using the SNPStats package in R software (Solé et al., 2006). Samples with a call rate $<0.90$ and heterozygosity of 3.0 standard deviations above or below than the observed mean were removed. For the quality control of mapped SNP, only autosomal SNP with call rate $>0.90$ and minor allele frequency $>0.03$ were considered. After this quality control, the genotype file contained 40,283 SNP markers and 476 samples, including 4 Holstein bulls, 23 Gir cows, $65 \mathrm{~F}_{1}$, and $384 \mathrm{~F}_{2}$ animals. Missing genotypes were imputed using FImpute software (Version 2.2) to ensure better statistical analysis effectiveness (Sargolzaei et al., 2011).

\section{Statistical Analyses}

Because the tick count data did not follow normal distribution, they were normalized using a natural log-transformation: ln (tick count +1 ). The bivariate model used was

$$
\mathbf{y}=\mathbf{X} \boldsymbol{\beta}+\mathbf{W a}+\mathbf{e},
$$

where $\mathbf{y}$ is the observations vector of the transformed tick count in rainy and dry seasons; $\boldsymbol{\beta}$ is the vector of fixed effects (i.e., contemporary group, sex, coat color and hair type, and the covariates, such as age, coat thickness, length and hair density); $\mathbf{a}$ is the vector of random additive genetic effects, assuming $\mathbf{a} \sim N\left(0 ; \mathbf{G}_{0}\right.$ 
$\otimes \mathbf{H})$, where $\mathbf{H}$ is a matrix combining genomic and pedigree information, as proposed by Aguilar et al. (2010) and $\mathbf{G}_{0}$ is the covariance matrix related to the additive genetic effect; $\mathbf{X}$ is the incidence matrix of fixed effects; $\mathbf{W}$ is the incidence matrix of random additive genetic effects; and $\mathbf{e}$ is the incidence vector of residual effect, assuming $\mathbf{e} \sim N\left(0 ; \mathbf{R}_{0} \otimes \mathbf{I}\right)$, where $\mathbf{I}$ is the identity matrix and $\mathbf{R}_{0}$ is the covariance matrix related to the residual effect.

Analyses for estimation of variance components and genetic parameters, as well as the GWAS, were performed using the single-step BLUP procedure (Aguilar et al.; 2010), as implemented in AIREMLF90 from the BLUPF90 family of programs (http://nce.ads.uga .edu/; Misztal et al., 2002). To map the loci explaining genetic differences in the evaluated trait linkage disequilibrium, blocks were identified in the genome based on linkage disequilibrium, genetic variance was estimated in 0.5-megabase Mbp overlapping windows using PostGSf90 software (http://nce.ads.uga.edu/; Aguilar et al., 2011). Percentage of additive genetic variance explained by window has been calculated based of genetic value of the each window of $0.5 \mathrm{Mbp}$ and the total additive genetic variance, as described by Wang et al. (2014). According to Habier et al. (2011), windows capture the QTL effect better than a single SNP, as several SNP are in linkage disequilibrium with a QTL, where each of these SNP explains a part of the QTL effect, allowing more precise estimation of this effect in a given chromosomal region. For the Manhattan plots construction, we selected nonoverlapping windows that exhibit the highest genetic variance using the mhtplot function of $\mathrm{R}$ software (version 3.3.1) to illustrate the genetic variance explained by each window.

\section{Gene Search and Gene Network Building}

According to Wang et al. (2014), the top 10 windows based on genetic variance were selected for each evaluated season (dry and rainy) to identify candidate genes from the initial and final coordinates of the each selected windows. Gene database of the National Center for Biotechnology Information (http://www.ncbi.nlm .nih.gov) was used to identify candidate genes located in the selected regions based on the UMD 3.1 assembly (Zimin et al., 2009) of the bovine genome.

From the identified candidate gene sets (rainy and dry season), we excluded noncoding RNA genes; those remaining were used for biological processes enrichment analyses. For that, the ClueGO application in Cytoscape (Bindea et al., 2009) was used based on a unilateral hypergeometric test and Bonferroni correction, which simultaneously analyzes 1 or more sets of genes and searches for a functional Gene Ontology (GO) term or pathways that establish relationships among genes.

Besides from the gene sets, promoter sequences (FASTA format) were obtained by considering 3,000 bp upstream and $300 \mathrm{bp}$ downstream from gene transcription start sites (Verardo et al., 2016) based on the bovine genome. These data were used as input to the TFMexplorer program (http://bioinfo.lifl.fr/TFM/TFME/ ) for the identification of enriched TF. This program uses weighting matrices from JASPAR database (http: //jaspar.binf.ku.dk/; Sandelin et al., 2004) to detect all potential transcription factor binding sites (TFBS) of a set of gene sequences and search for overrepresented TFBS. This program extracts significant groups (TFBS regions of the selected gene sequences associated with a factor) by calculating a scoring function threshold that is chosen to give a $P$-value equal to or less than $10^{-3}$ for each position in each sequence, as described in Touzet and Varré (2007).

The TF list was then analyzed in Cytoscape software (Shannon et al., 2003) using the Biological Networks Gene Ontology tool (Maere et al., 2005) to determine significantly overrepresented functional GO terms. Based on the overrepresented biological processes in Biological Networks Gene Ontology tool and evidence of literature review related to the studied trait, we were able to identify the TF most related to tick resistance, allowing us to generate a gene-TF interaction network. Gene-TF network analysis was performed in Cytoscape software based on the number of TFBS (connections with the selected TF) in each gene to determine the strongest associations with tick counts that will aid in the identification of the most likely candidate genes.

\section{Assignment of Breed of Origin of Alleles}

To assign the genetic origin of marker alleles in the $\mathrm{F}_{2}$ population, the breed origin of alleles (BOA) approach (Vandenplas et al., 2016) was used with the parameter settings recommended by Sevillano et al. (2016). The BOA approach consists of 3 steps, namely (1) phasing of pure and crossed animal haplotypes; (2) determining the unique haplotypes for each pure breed; and (3) assigning the breed of origin to alleles observed in $\mathrm{F}_{2}$ animals based on the determined unique haplotypes.

The software AlphaPhase 1.1 (Hickey et al., 2011) was chosen for haplotype phasing. The phasing step was performed using pedigree, and during the second step of the BOA approach a relaxation factor of $20 \%$ was used, which represents the maximum percentage of haplotype copies that can be observed in a popula- 
tion of a different breed. If the percentage of haplotype copies identified in a single breed is less than (100relaxation factor), the breed of origin of this haplotype is defined as unknown.

Crossing between Bos taurus and Bos indicus animals results in the formation of long chromosome segments in $\mathrm{F}_{2}$ crossed animals, which are expected to have the same origin. These segments allow a clear classification of origin of the SNP as Bos taurus or Bos indicus (Bolormaa et al., 2013).

After the origin of alleles analysis for the entire population, $\mathrm{F}_{2}$ animals were classified as resistant $(10 \%$ of animals with the lowest genomic breeding values for the number of ticks) or susceptible (10\% of animals with the highest genomic breeding values). In these selected samples, the adjacent SNP close to genes in the networks were used to identify the origin of their alleles. The SNP alleles from each group were assigned to their breed of origin and paternity and classified into 4 types: father $\mathrm{H}$ (Holstein), father G (Gir), mother H (Holstein), and mother G (Gir). After this classification, the alleles of each SNP were quantified and classified according to the breed of origin using the Chi-squared test to compare the segregation between resistant and susceptible groups.

\section{RESULTS AND DISCUSSION}

Heritability estimates for tick counts were $0.40 \pm 0.11$ in the rainy season and $0.54 \pm 0.11$ in the dry season. In other studies, heritability for tick resistance ranged from 0.09 to 0.37 (Prayaga et al., 2009; Machado et al., 2010; Turner et al., 2010). In a previous study using 180 microsatellite markers in this same $\mathrm{F}_{2}$ experimental population, Machado et al. (2010) estimated a lower heritability $(0.21 \pm 0.12)$. A total of $40,283 \mathrm{SNP}$ markers were used, which allowed identifying a greater number of QTL regions for tick count, contributing to the estimation of a higher heritability. The different statistical models applied in each experiment may also explain the different estimates of heritability in both studies. Moreover, Machado et al. (2010) analyzed the data using a single-trait model, so the correlation (0.36) between counts made in the same individual in 2 seasons was estimated using Pearson product-moment correlation coefficient. On the other hand, we estimated the genetic correlation (0.96) between tick count in each season using bivariate analyses. Independent of the statistical methodologies and molecular tools used to assess animal genotypes, our results indicate the presence of genetic variability for tick counts. According to Turner et al. (2010), the selection for resistance would not affect the milk production in cattle. Those authors identified a low correlation between the effects of alleles involved in milk production and tick counts in an association study using SNP in Bos taurus animals from Australia. Prayaga et al. (2009) also reported low and nonsignificant genetic correlation between tick counts and several production traits, confirming that selection for this trait does not promote unfavorable effects on other economically important traits.

Based on GWAS results, we identified 7,327 windows with mean density of 9 SNP per window (Figures 1 and 2 ). We selected 10 windows with the highest percentage of genetic variance explained distributed in chromosomes 10 and 23. Other studies, which evaluated tick resistance in cattle, also reported several QTL on the same chromosomes (Machado et al., 2010; Turner et al., 2010; Mapholi et al., 2016). All windows identified in the rainy season were also found in the dry season, differing only by the genetic variance explained by each window (Table 1). The window with the highest genetic variance was located in Bos taurus autosome 23 and was the same for both seasons, explaining 1.80 and $1.84 \%$ for the rainy and dry seasons, respectively. In the previous study performed by Machado et al. (2010), the identified QTL showing the highest phenotypic variance was also found on chromosome 23 for both seasons. The other windows followed the same pattern of additive genetic variance between both seasons, a fact that might be due to the high genetic correlation (0.96) between the traits evaluated for dry and rainy seasons. The percentage of genetic variances explained by all selected windows is noticeable, $5.34 \%$ for each season, and suggests the existence of a strong relationship between these genome regions and the resistance to bovine tick in this population.

From the windows selected in both seasons, 60 genes encoding proteins with different functions were annotated. To better understand the functions of these tick resistance genes, we performed a biological process analyses (Figure 3). In this GO network, we identified genes biological process enrichment involved in relevant immune functions, such as TREM1, TREM2 (window 6, Table 1), and CD83 (window 10, Table 1). Triggering receptor expressed on myeloid cells (TREM) are important regulators of immune response, as they are potent amplifiers of inflammatory responses (Genua et al., 2014). Gene TREM1 has been related to monocytes and neutrophils blood circulating, macrophages, dendritic cells (DC) and activation of T-cells, CD86, and major histocompatibility complex (MHC) class II (Schenk et al., 2007; Chen et al., 2008; Sharif and Knapp, 2008). The expression of TREM2 was detected in DC, monocytes, and macrophages (Turnbull et al., 2006; Seno et al., 2009; Bosco et al., 2011); DC, along 
with CC chemokine receptors 7 , increase expression in dendritic cells of costimulatory molecule (B7) and MHC class I and II (Gao et al., 2017).

The CD83 gene is an immunoglobulin superfamily member and is regulated during DC activation, being used to identify the maturation or activation of DC in peripheral circulation (Breloer and Fleischer, 2008). Gene CD83 is expressed in most immune cells such as B cells (Kretschmer et al., 2007), monocytes and macrophages (Cao et al., 2005), neutrophils (Yamashiro et al., 2000), and a regulatory subset of natural killers cells (Mailliard et al., 2005), thus showing its essential role in the initiation and regulation of innate and adaptive immune responses. It acts in the stimulation of immature and memory $\mathrm{T}$ cells by activation of $\mathrm{DC}$ (Aerts-Toegaert et al., 2007), thymic maturation and activation of $\mathrm{CD}^{+}$and $\mathrm{CD}^{+}$(Ju et al., 2016), maturation and maintenance of peripheral lymphocyte $\mathrm{B}$ homeostasis (Lüthje et al., 2008), and in the increased expression of MHC class I and CD86 (Tze et al., 2011). Thus, this gene also has functions potentially involved with the physiological response to tick infestation in cattle, what makes it a candidate gene for this trait along with TREM1 and TREM2. Carvalho et al. (2014) identified potential tick resistance genes from this same family (CD14, CD5L, CD55, CD68,CD84, CD86) when analyzing gene expression microarrays in the first hours of tick infestation in the same experimental population.

We performed in silico analyses of regulatory sequences for all detected genes and found 25 significantly enriched TF $(P<0.0001)$. The TF list was analyzed to determine which functional GO terms were significantly overrepresented. The TF most associated with tick counts, based on biological processes and literature review (Table 2), were then chosen to generate a geneTF network (Figure 4), which allowed the identification of candidate genes for tick resistance.

Among the analyzed TF in the network, 2 nodes were linked to a high number of genes (TAL1::TCF3 and $P A X 5)$. The TCF3 transcription factor is a regulator of lymphopoiesis B and acts in the first detectable stages of B-cell involvement, development, and maturation (van der Veer et al., 2014). It is also an important regulator of $\mathrm{T}$ cell development and its deficiency in

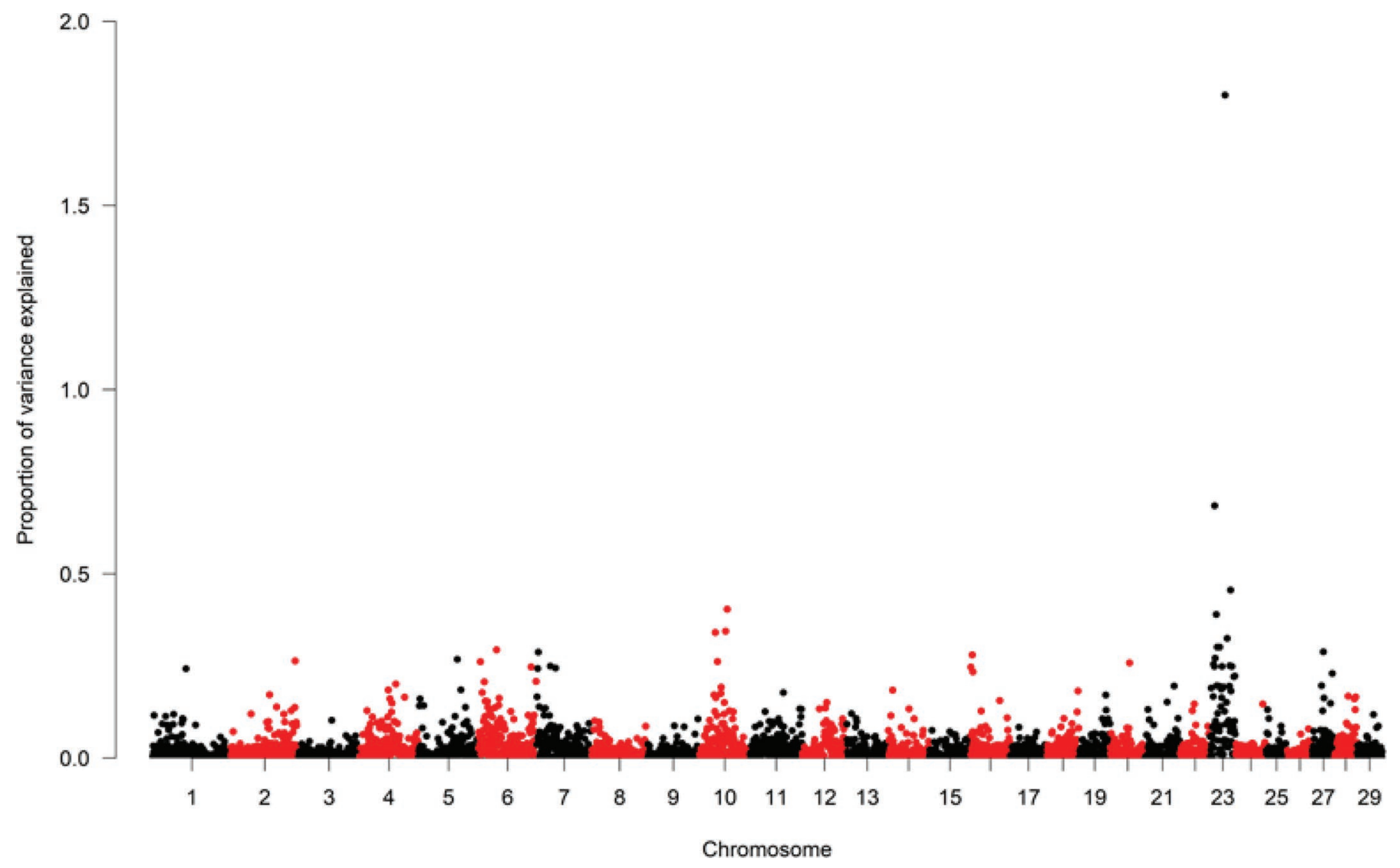

Figure 1. Manhattan plot of additive genetic variance explained by nonoverlapping windows in the experimental Holstein $\times$ Gir $\mathrm{F}_{2}$ population evaluated for cattle resistance to tick in the rainy season. Color version available online. 
Table 1. Top 10 selected windows for percentage of additive genetic variance for the rainy and dry seasons in an experimental Holstein $\times$ Gir $\mathrm{F}_{2}$ population evaluated for cattle resistance to tick

\begin{tabular}{|c|c|c|c|c|c|}
\hline Window & Chromosome & Start $^{1}$ & End $^{2}$ & Var. Exp. Rainy ${ }^{3}$ & Var. Exp. Dry ${ }^{4}$ \\
\hline 2 & 23 & $9,712,645$ & $10,167,082$ & 0.68 & 0.69 \\
\hline 5 & 23 & $12,997,137$ & $13,484,531$ & 0.39 & 0.38 \\
\hline 6 & 10 & $54,341,869$ & $54,787,499$ & 0.34 & 0.33 \\
\hline 7 & 10 & $33,343,859$ & $33,774,666$ & 0.34 & 0.36 \\
\hline 10 & 23 & $14,992,700$ & $15,465,413$ & 0.30 & 0.30 \\
\hline
\end{tabular}

${ }^{1}$ Position in base pair of the first SNP in the window.

${ }^{2}$ Position in base pair of the last SNP in the window.

${ }^{3}$ Percentage of additive genetic variance explained by each window for rainy season.

${ }^{4}$ Percentage of additive genetic variance explained by each window for dry season.

mice leads to defects in the selection and differentiation of thymocytes (Aspland et al., 2001). The TAL1 is the master regulator of hematopoietic stem/progenitor cells in humans (Benyoucef et al., 2015) and it is essential to formation but not involved in the maintenance of hematopoietic stem cells in adults (Capron et al., 2006). Gene PAX5 is involved in the entry of common lymphoid cells into B cell line. In the absence of TCF3, $P A X 5$ is responsible for in vivo activation of B lymphocyte transcription program (Souroullas et al., 2009).

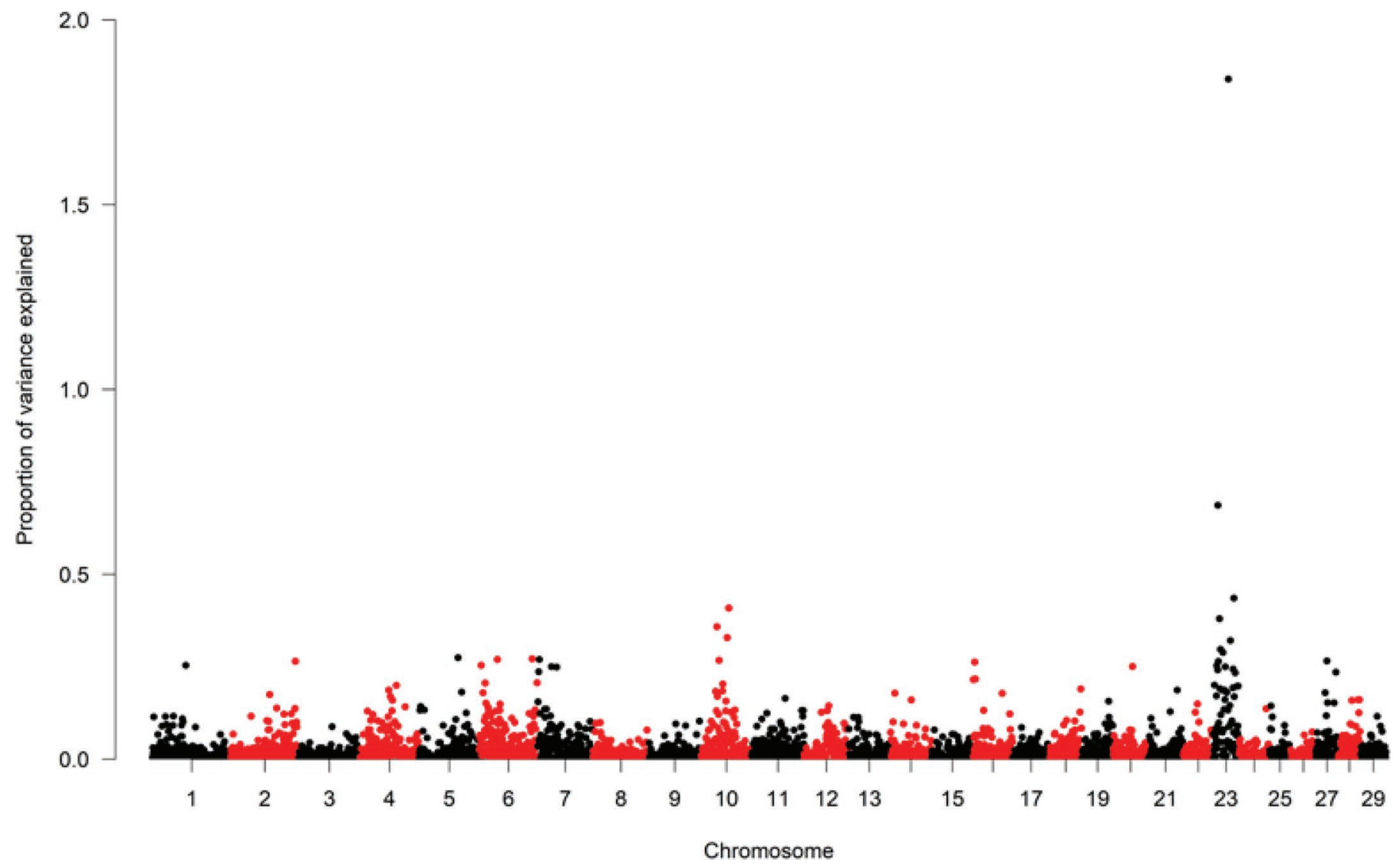

Figure 2. Manhattan plot of additive genetic variance explained by nonoverlapping windows in the experimental Holstein $\times$ Gir $\mathrm{F}_{2}$ population evaluated for cattle resistance to tick in the in the dry season. Color version available online. 


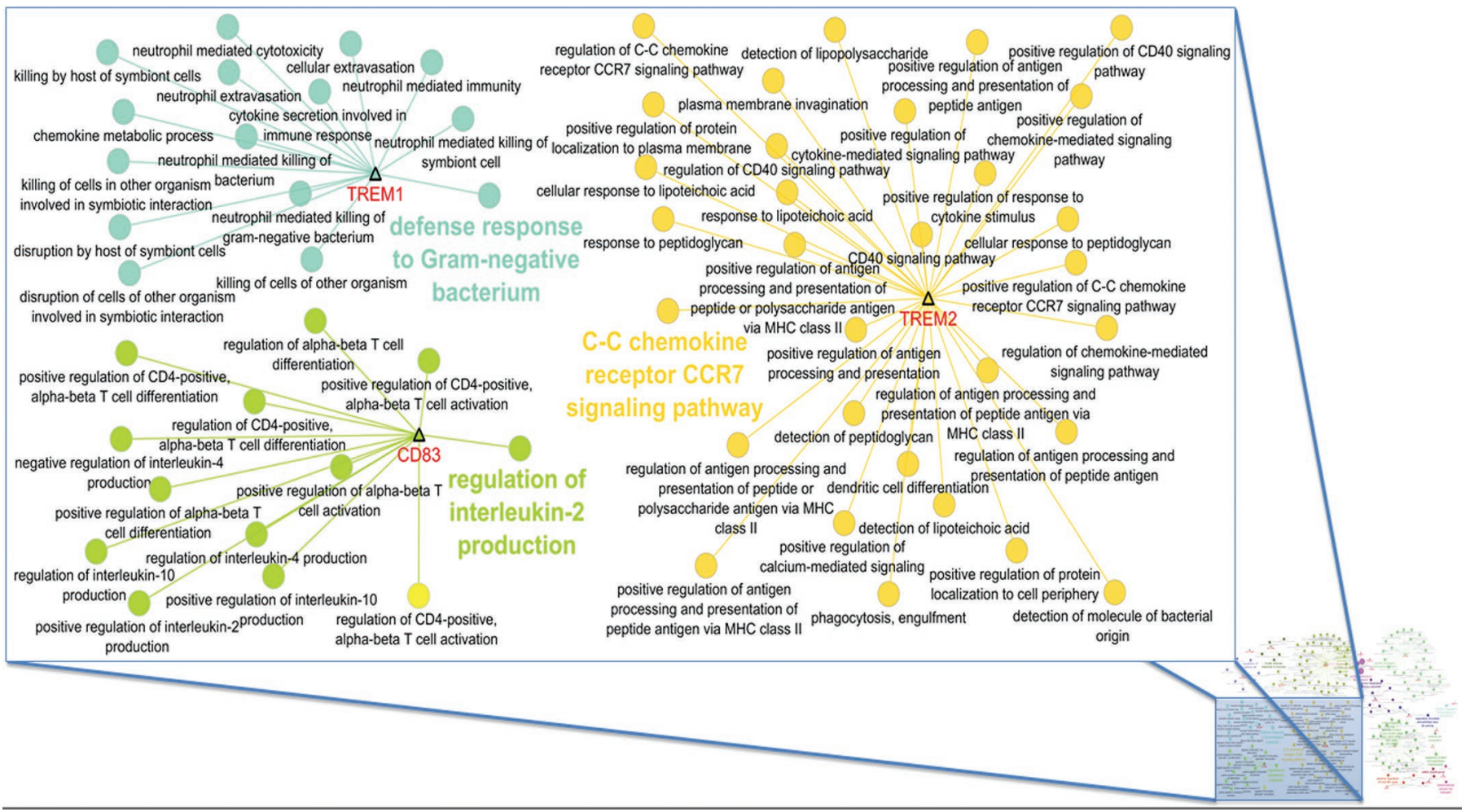

Figure 3. Functional networks showing gene interactions (triangle nodes) related to cattle tick resistance in dry and rainy seasons and the relationship across genes and their subnetworks related to immune system biological processes. Color version available online.

We also found $4 \mathrm{TF}$ showing a high number of connections in the gene-TF network: NFIL3, EGR1, SOX10, and $R E L$. Gene NFIL 3 is believed to be associated with the function of adaptive immune lines and natural killer cell development (Seillet et al., 2014). Genes EGR1 (Carter et al., 2007), SOX10 (Fufa et al., 2015), and
REL (Hayden and Ghosh, 2011; Herrington and Nibbs, 2016) were found to be associated with prereceptormediated differentiation of thymocytes, proliferation and survival of melanocytes and melanogenesis, and key regulation of inducible gene expression in the immune system, respectively.

Table 2. Enriched transcription factors (TF) associated with genes identified for cattle tick counts in rainy and dry season, based on their biological process and literature review (data obtained in an experimental Holstein $\times$ Gir $\mathrm{F}_{2}$ population evaluated for bovine tick resistance)

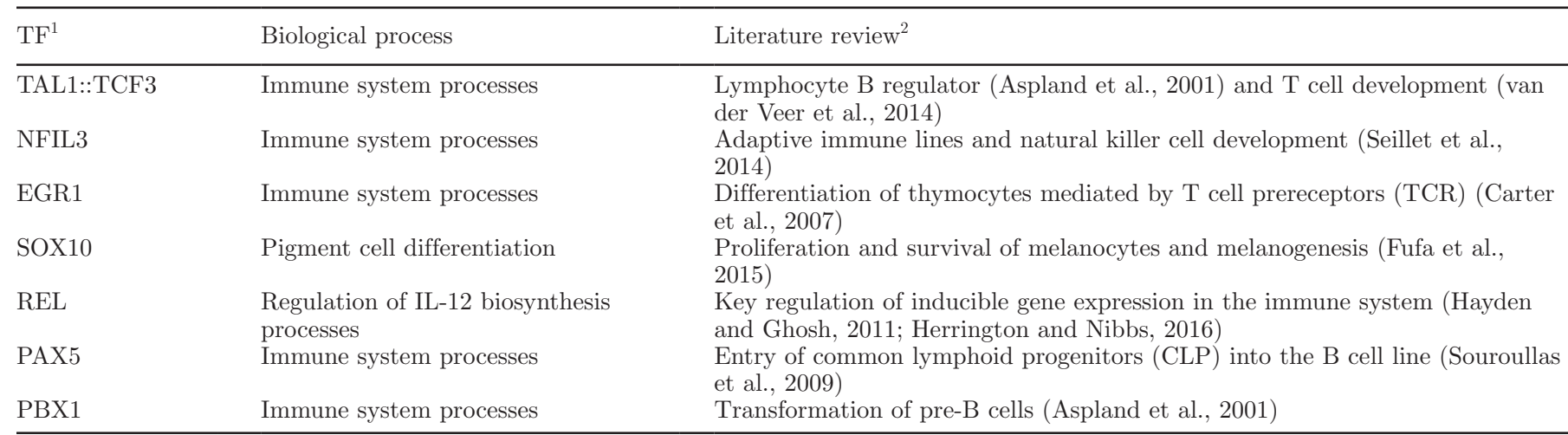

${ }^{1}$ TAL1 = T-cell acute lymphocytic leukemia 1; TCF3 = transcription factor 3 ; NFIL3 = nuclear factor, interleukin 3 regulated; EGR1 = early growth response 1; SOX10 = SRY (sex determining region Y)-box 10; REL = REL proto-oncogene, NF-kB subunit; PAX5 = paired box 5; PBX1 $=$ pre-B-cell leukemia transcription factor 1 .

${ }^{2}$ The cited literature studies are just a sample from the vast available literature. 
From the gene-TF network, candidate genes for tick counts were highlighted based on TFBS. The MYO5A gene (window 3 , Table 1 ) showed connections to a set of TF (TALL3::TCF3, NFIL3, EGR1, and PAX5). This gene encodes the myosin Va protein found in melanocytes and, along with other proteins, assists in the melanosomes transport, which are structures that produce the melanin pigment responsible for pigmentation of skin, hair, and eyes (Pastural et al., 2000; Hume and Seabra, 2011). Melanocytes play an important role in the innate immune response, controlling microbial infection and inflammation, as these cells contribute to phagocytosis of invading pathogens. As they present antigen to the competent immune cells, melanocytes produce key cytokines, such as IL-1 $\beta$, IL-6, and tumor necrosis factor- $\alpha$, as well as chemokines, which alert macrophages, neutrophils, and T cells. Melanocytes can further express pattern recognition receptors, which

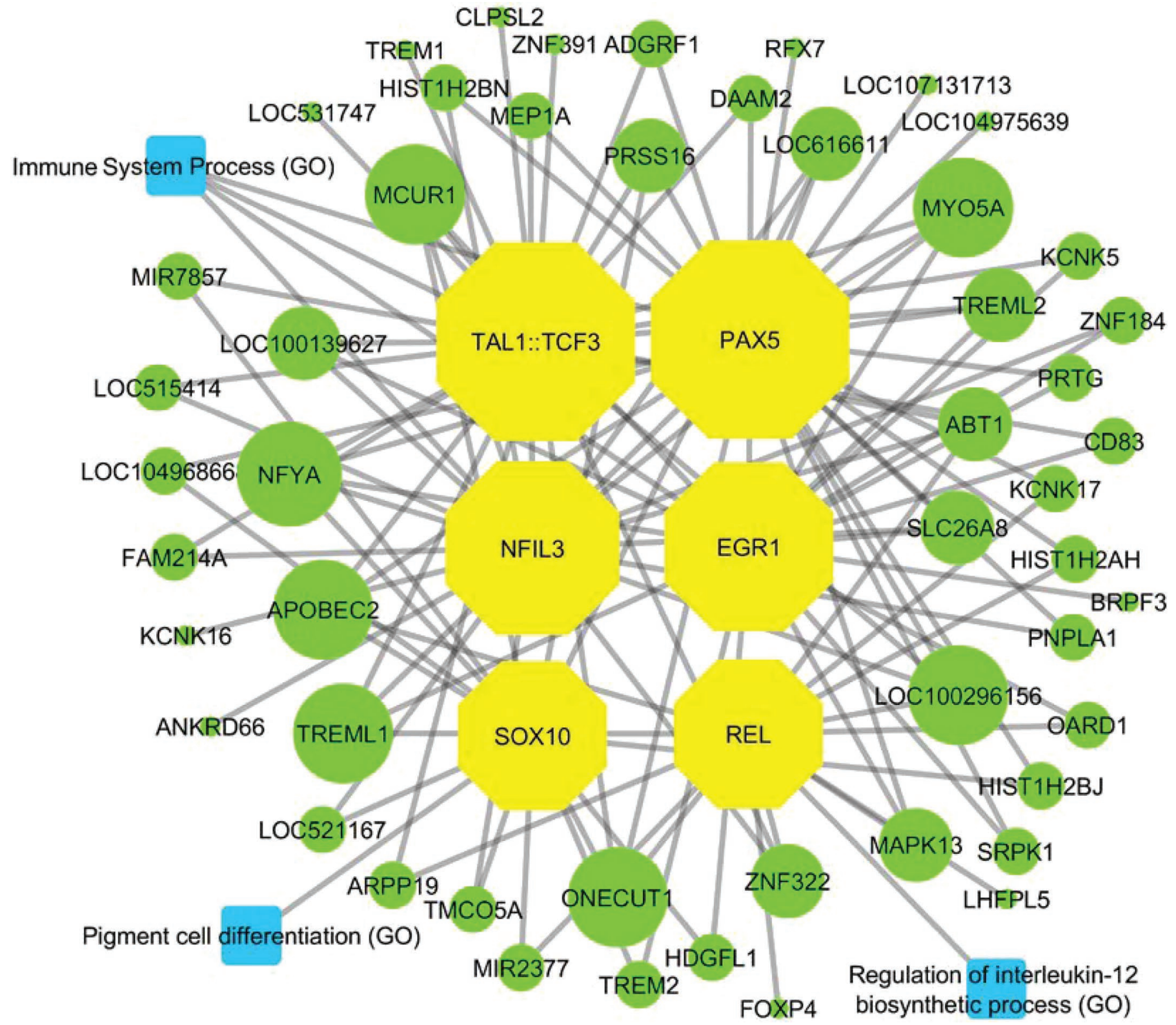

Figure 4. Gene-transcription factor (TF) network: genes located in the top 10 windows for tick counts in dry and rainy seasons (circular/ green nodes) and their associated TF (octagonal/yellow nodes). The node size corresponds to the network analyses (Cytoscape; Shannon et al., 2003) in which the larger nodes correspond to a higher edge density associated with the number of TF binding sites. Square/blue nodes are the biological processes related to TF (Gene Ontology terms). Data obtained in an experimental Holstein $\times$ Gir $\mathrm{F}_{2}$ population evaluated for cattle tick resistance. Color version available online. 
detect specific pathogenic structures and induce the production of Type I IFN and other immune system proteins (Gasque and Jaffar-Bandjee, 2015).

The TREML1 gene (window 6, Table 1) showed connection to TAL1::TCF3, REL, PAX5, and EGR1 TF. The TREM-like transcript-1 (TLT-1/TREML1) belongs to the TREM family and is known to be selectively expressed in activated platelets and to facilitate platelet aggregation by binding to fibrinogen, acting as a chemotactic mediator in the attachment of thrombi to endothelium vascular (Esponda et al., 2015). Its soluble form ( $s T L T-1)$ participates in the regulation of inflammation during sepsis, attenuating leukocyte activity and modulating the interference between platelets and neutrophils (Morales et al., 2010; Derive et al., 2012).

The PRSS16 gene (window 8, Table 1), which did not share any ontology in the biological processes network (Figure 3), was related to the most enriched TF (TAL1::TCF3 and PAX5) and shows evidence of being associated with the immune system (Brisson et al., 2015). The importance of this gene is paramount in the positive regulation of $\mathrm{CD} 4^{+} \mathrm{T}$ lymphocytes, as it encodes the thymus-specific serine protein, which is predominantly expressed by the thymic epithelial cells in the cortex, and is involved in the generation of peptides presented by class II MHC molecules in the thymus (Viret et al., 2011b; Fornari et al., 2012). Thymus-specific serine protein is required for the intracellular development of cells expressing $\mathrm{T}$ cell receptors, contributing to the diversification of $\mathrm{T}$ cell receptors repertoire of endogenous functional CD4 T cells in the thymus (Viret et al., 2011a). These genes are also involved in the organism defense against pathogens and injuries, and thus may be involved in bovine resistance against ticks.

Among all genes of the immune system associated with the host resistance to pathogens, the major histocompatibility complex genes [MHC or bovine lymphocyte antigen (BoLA)] are the most studied. Located on chromosome 23, these genes encode cell surface glycoproteins, which work as receptors on antigen presenting cells, connecting and presenting antigenic peptides to $\mathrm{T}$ lymphocytes, thus triggering the onset of immune response in the host (Tizard, 2008). In the same position on chromosome 23, Machado et al. (2010) found highly significant QTL associated with tick counts using the same experimental population as the current work. The association between MHC class II alleles and tick resistance was also reported by Martinez et al. (2006), who found an association between a low number of ticks and gene-BoLA-DRB 3.2, alleles 18, 20, and 27, suggesting that BoLA-DRB 3.2 alleles could be used to aid in the selection of tick-resistant animals. Other studies also reported a significant relationship between MHC genes and tick counts (Acosta-Rodríguez et al., 2005; Untalan et al., 2007). Most of the genes identified in our study (e.g., TREM1, TREM2, CD83 and PRSS16) showed important roles associated with the activities of MHC class I and II, suggesting that these genes could be involved in the host immune response to tick infestation.

Based on the networks, we selected genes to assess the origin of alleles associated with bovine tick resistance. Considering the LD between SNP and genes, the physical position of TREM1, TREM2, CD83, MYO5A, TREML1, and PRSS16 were annotated for adjacent SNP selection. We selected a total of 11 SNP: 3 SNP in window 3,4 in window 6,2 in window 8 , and 2 in window 10 (Table 1). The animals were grouped as resistant or susceptible animals based on their genomic breeding values. Thus, the alleles of the selected SNP were classified and quantified according to their breed of origin and paternity: $\mathrm{HH}$ for both paternal and maternal alleles originated from Holstein breed, GG for both paternal and maternal alleles originated from Gir breed, HG for paternal allele originated from Holstein breed and maternal allele from Gir breed, and GH for paternal allele originated from Gir breed and maternal allele from Holstein breed. According to de Roos et al. (2009), the effects of SNP on the phenotype depend on the linkage disequilibrium between marker and QTL, but this linkage disequilibrium can differ between Bos taurus and Bos indicus, as they are distinct subspecies, which makes the search for the origin of alleles extremely important.

Based on Chi-squared test applied to resistant and susceptible animal genotypes, we observed 3 significant SNP $(P<0.05)$ in resistant animals (SNP 8, 10 and 11) and 9 in susceptible animals (SNP 1 to 9) (Table 3), which showed a deviation of the expected gametic segregation of $25 \%$ for each genotypic class $(1 \mathrm{HH}, 1 \mathrm{GG}$, $1 \mathrm{HG}, 1 \mathrm{GH})$. In resistant animals, the average proportion of animals for GG significant SNP was $44.8 \%$, whereas animals classified as HH were represented by only $11.3 \%$. On the other hand, in susceptible animals, $\mathrm{HH}$ represented $44.6 \%$, on average, whereas GG animals represented $9.3 \%$ of the animals in this group. Based on these findings, it was observed that most resistant animals inherited both Gir alleles, whereas a small part received both Holstein alleles. Machado et al. (2010), evaluating the same experimental population as our study, identified a QTL with a negative additive effect on chromosome 5 from Holstein breed, showing that alleles from this susceptible breed also contributed to the increased resistance of the evaluated animals for tick resistance.

In the 2 evaluated groups, animals classified as HG and GH represented 43.9 and $46 \%$ of resistant and susceptible animals, respectively. As we were not able to 
Table 3. Percentage of individuals classified by breed of origin and paternity of each SNP allele analyzed in tick resistant and susceptible animals in an experimental Holstein $\times$ Gir $\mathrm{F}_{2}$ population

\begin{tabular}{|c|c|c|c|c|c|c|c|c|c|c|c|}
\hline \multirow[b]{2}{*}{ Alleles } & \multicolumn{3}{|c|}{ Window 3} & \multicolumn{4}{|c|}{ Window 6} & \multicolumn{2}{|c|}{ Window 8} & \multicolumn{2}{|c|}{ Window 10} \\
\hline & SNP1 & SNP2 & SNP3 & $\mathrm{SNP} 4$ & SNP5 & SNP6 & SNP7 & SNP8 & SNP9 & SNP10 & SNP11 \\
\hline $\mathrm{HH}^{1}$ & 11.8 & 12.1 & 12.5 & 18.2 & 18.2 & 20.0 & 20.7 & $16.7^{*}$ & 17.1 & $8.6^{*}$ & $8.8^{*}$ \\
\hline $\mathrm{GG}^{2}$ & 38.2 & 39.4 & 37.5 & 39.4 & 39.4 & 33.3 & 34.5 & $44.4^{*}$ & 42.9 & $45.7^{*}$ & $44.1^{*}$ \\
\hline $\mathrm{HG}^{3}$ & 29.4 & 27.3 & 28.1 & 27.3 & 27.3 & 30.0 & 27.6 & $25.0^{*}$ & 25.7 & $31.4^{*}$ & $32.4^{*}$ \\
\hline $\mathrm{GH}^{4}$ & 20.6 & 21.2 & 21.9 & 15.2 & 15.2 & 16.7 & 17.2 & $13.9^{*}$ & 14.3 & $14.3^{*}$ & $14.7^{*}$ \\
\hline \multicolumn{12}{|c|}{ Susceptible animals } \\
\hline GG & $10.5^{*}$ & $10.8^{*}$ & $10.5^{*}$ & $5.9^{*}$ & $6.5^{*}$ & $6.5^{*}$ & $6.3^{*}$ & $13.5^{*}$ & $13.5^{*}$ & 23.3 & 22.6 \\
\hline HG & $31.6^{*}$ & $32.4^{*}$ & $31.6^{*}$ & $32.4^{*}$ & $29.0^{*}$ & $29.0^{*}$ & $28.1^{*}$ & $16.2^{*}$ & $16.2^{*}$ & 13.3 & 12.9 \\
\hline $\mathrm{GH}$ & $15.8^{*}$ & $16.2^{*}$ & $15.8^{*}$ & $20.6^{*}$ & $22.6^{*}$ & $22.6^{*}$ & $21.9^{*}$ & $16.2^{*}$ & $16.2^{*}$ & 20.0 & 19.4 \\
\hline
\end{tabular}

${ }^{1}$ Paternal and maternal alleles originated from Holstein breed.

${ }^{2}$ Paternal and maternal alleles originated from Gir breed.

${ }^{3}$ Paternal allele originated from Holstein breed and maternal from Gir breed.

${ }^{4}$ Paternal allele originated from Gir breed and maternal from Holstein breed.

${ }^{*}$ Significant SNP for allele origin in the chi-squared test $(P<0.05)$.

identify influence of the origin and paternity breed of the alleles in the SNP evaluated in these 2 classes, the phenotypes could be influenced by other factors not detected by our study, such as the presence of regulatory genes. As tick resistance is a polygenic trait, other genes with lower and epistatic effects, not detected in this GWAS analysis, may also have influenced this phenotype.

In summary, GWAS allowed us to identify candidate genes for tick resistance in an experimental $\mathrm{F}_{2}$ ( Gir $\times$ Holstein) population. The network analysis highlighted gene interactions that were consistent with the biology of the immune system and provided known TF that allowed the identification of candidate genes for cattle tick resistance in both rainy and dry seasons (e.g., TREM1, TREM2, TREML1, CD83, MYO5A, and PRSS16). According to origin of allele analysis, we observed that most of the animals classified as resistant showed 2 alleles from Gir breed, whereas the susceptible animals showed alleles from Holstein breed. Based on these results, the identified genes may be deeply investigated in additional experiments aiming to validate their effects on tick resistance phenotype in cattle.

\section{ACKNOWLEDGMENTS}

We thank Embrapa Dairy Cattle Research Center (EMBRAPA), Fundação de Amparo à Pesquisa do Estado de Minas Gerais (FAPEMIG), Coordenação de Aperfeiçoamento de Pessoal de Nível Superior (CAPES), Conselho Nacional de Desenvolvimento Científico e Tecnológico ( $\mathrm{CNPq})$, and Ministério da Ciência Tecnologia e Inovação (MCTI)/Conselho Nacional de
Desenvolvimento Científico e Tecnológico (CNPq)/ Instituto Nacional de Ciência e Tecnologia - Ciência Animal (INCT-CA) for the financial support, Embrapa Dairy Cattle Research Center for providing the data needed to carry out this study, and Mario P. L. Calus (Wageningen University \& Research Animal Breeding and Genomics, Wageningen, the Netherlands) for his assistance in BOA methodology. The authors wish to thank and acknowledge all the team effort and the visionary work done by the late Mário Luiz Martinez, former leader of this project at Embrapa Dairy Cattle Research Center.

\section{REFERENCES}

Acosta-Rodríguez, R., R. Alonso-Morales, S. Balladares, H. FloresAguilar, Z. García-Vazquez, and C. Gorodezky. 2005. Analysis of BoLA class II microsatellites in cattle infested with Boophilus microplus ticks: Class II is probably associated with susceptibility. Vet. Parasitol. 127:313-321. https://doi.org/10.1016/j.vetpar.2004 .10 .007 .

Aerts-Toegaert, C., C. Heirman, S. Tuyaerts, J. Corthals, J. L. Aerts, A. Bonehill, K. Thielemans, K. Breckpot, and K. Breckpot. 2007. CD83 expression on dendritic cells and T cells: Correlation with effective immune responses. Eur. J. Immunol. 37:686-695. https:/ /doi.org/10.1002/eji.200636535.

Aguilar, I., I. Misztal, D. L. Johnson, A. Legarra, S. Tsuruta, and T. J. Lawlor. 2010. Hot topic: A unified approach to utilize phenotypic, full pedigree, and genomic information for genetic evaluation of Holstein final score. J. Dairy Sci. 93:743-752. https://doi.org/10 $.3168 /$ jds.2009-2730.

Aguilar, I., I. Misztal, A. Legarra, and S. Tsuruta. 2011. Efficient computation of the genomic relationship matrix and other matrices used in single-step evaluation. J. Anim. Breed. Genet. 128:422428. https://doi.org/10.1111/j.1439-0388.2010.00912.x.

Aspland, S. E., H. H. Bendall, and C. Murre. 2001. The role of E2APBX1 in leukemogenesis. Oncogene 20:5708-5717. https://doi .org/10.1038/sj.onc.1204592. 
Ayres, D. R., R. J. Pereira, A. A. Boligon, F. Baldi, V. M. Roso, and L. G. Albuquerque. 2015. Genetic parameters and investigation of genotype $\times$ environment interactions in Nellore $\times$ Hereford crossbred for resistance to cattle ticks in different regions of Brazil. J. Appl. Genet. 56:107-113. https://doi.org/10.1007/s13353-014 $-0238-5$.

Benyoucef, A., J. Calvo, L. Renou, M.-L. Arcangeli, A. Van Den Heuvel, S. Amsellem, M. Mehrpour, J. Larghero, E. Soler, I. Naguibneva, and F. Pflumio. 2015. The SCL / TAL1 transcription factor represses the stress protein DDiT4 / REDD1 in human hematopoietic stem / progenitor cells. Stem Cells 33:2268-2279.

Bindea, G., B. Mlecnik, H. Hackl, P. Charoentong, M. Tosolini, A. Kirilovsky, W. H. Fridman, F. Pagès, Z. Trajanoski, and J. Galon. 2009. ClueGO: A Cytoscape plug-in to decipher functionally grouped gene ontology and pathway annotation networks. Bioinformatics 25:1091-1093. https://doi.org/10.1093/bioinformatics/ btp101.

Bolormaa, S., J. E. Pryce, K. E. Kemper, B. J. Hayes, Y. Zhang, B. Tier, W. Barendse, A. Reverter, and M. E. Goddard. 2013. Detection of quantitative trait loci in Bos indicus and Bos taurus cattle using genome-wide association studies. Genet. Sel. Evol. 45:43. https://doi.org/10.1186/1297-9686-45-43.

Bosco, M. C., D. Pierobon, F. Blengio, F. Raggi, C. Vanni, M. Gattorno, A. Eva, F. Novelli, P. Cappello, M. Giovarelli, and L. Varesio. 2011. Hypoxia modulates the gene expression profile of immunoregulatory receptors in human mature dendritic cells: Identification of TREM-1 as a novel hypoxic marker in vitro and in vivo. Blood 117:2625-2639. https://doi.org/10.1182/blood-2010 $-06-292136$.

Breloer, M., and B. Fleischer. 2008. CD83 regulates lymphocyte maturation, activation and homeostasis. Trends Immunol. 29:186-194. https://doi.org/10.1016/j.it.2008.01.009.

Brisson, L., L. Pouyet, P. N'guessan, S. Garcia, N. Lopes, G. Warcollier, J. L. Iovanna, and A. Carrier. 2015. The thymus-specific serine protease TSSP/PRSS16 is crucial for the antitumoral role of CD4+ T cells. Cell Reports 10:39-46. https://doi.org/10.1016/j .celrep.2014.12.009.

Cao, W., S. H. Lee, and J. Lu. 2005. CD83 is preformed inside monocytes, macrophages and dendritic cells, but it is only stably expressed on activated dendritic cells. Biochem. J. 385:85-93. https: //doi.org/10.1042/BJ20040741.

Capron, C., Y. Lécluse, A. L. Kaushik, A. Foudi, C. Lacout, D. Sekkai, I. Godin, O. Albagli, I. Poullion, F. Svinartchouk, E. Schanze, W. Vainchenker, F. Sablitzky, A. Bennaceur-Griscelli, and D. Duménil. 2006. The SCL relative LYL-1 is required for fetal and adult hematopoietic stem cell function and B-cell differentiation. Blood 107:4678-4686. https://doi.org/10.1182/blood-2005-08-3145.

Cardoso, C. P., B. F. Silva, D. S. Gonçalves, N. J. Tagliari, M. E. Saito, and A. F. T. Amarante. 2014. Resistência contra ectoparasitas em bovinos da raça crioula lageana e meio-sangue angus avaliada em condições naturais. Pesqui. Vet. Bras. 34:141-146. https:/ /doi.org/10.1590/S0100-736X2014000200008.

Carter, J. H., J. M. Lefebvre, D. L. Wiest, and W. G. Tourtellotte. 2007. Redundant role for early growth response transcriptional regulators in thymocyte differentiation and survival. J. Immunol. 178:6796-6805.

Carvalho, W. A., R. Domingues, M. C. de Azevedo Prata, M. V. G. B. da Silva, G. C. de Oliveira, S. E. F. Guimarães, and M. A. Machado. 2014. Microarray analysis of tick-infested skin in resistant and susceptible cattle confirms the role of inflammatory pathways in immune activation and larval rejection. Vet. Parasitol. 205:307-317. https://doi.org/10.1016/j.vetpar.2014.07.018.

Chen, L. C., J. D. Laskin, M. K. Gordon, and D. L. Laskin. 2008. Regulation of TREM expression in hepatic macrophages and endothelial cells during acute endotoxemia. Exp. Mol. Pathol. 84:145-155. https://doi.org/10.1016/j.yexmp.2007.11.004.

de Roos, A. P., B. J. Hayes, and M. E. Goddard. 2009. Reliability of genomic predictions across multiple populations. Genetics 183:1545-1553. https://doi.org/10.1534/genetics.109.104935.

Derive, M., Y. Bouazza, N. Sennoun, S. Marchionni, L. Quigley, V. Washington, F. Massin, J.-P. Max, J. Ford, C. Alauzet, B. Levy,
D. W. McVicar, and S. Gibot. 2012. Soluble trem-like transcript-1 regulates leukocyte activation and controls microbial sepsis. J. Immunol. 188:5585-5592. https://doi.org/10.4049/jimmunol .1102674 .

Esponda, O. L., R. Hunter, J. R. R. Del Río, and A. V. Washington. 2015. Levels of soluble TREM-like transcript 1 in patients presenting to the emergency department with chest pain. Clin. Appl. Thromb. Hemost. 21:30-34. https://doi.org/10.1177/ 1076029614547298.

Ferro, F. R. A., C. C. C. Neto, M. R. T. Filho, S. T. S. Ferri, and Y. C. Montaldo. 2010. Efeito do estresse calórico no desempenho reprodutivo de vacas leiteiras. Revista Verde de Agroecologia e Desenvolvimento Sustentável 5:1-25.

Fornari, T. A., M. M. Marques, C. Nguyen, A. Carrier, and G. A. Passos. 2012. Transcription profiling of Prss16 (Tssp) can be used to find additional peptidase genes that are candidates for self-peptide generation in the thymus. Mol. Biol. Rep. 39:4051-4058. https:// doi.org/10.1007/s11033-011-1186-3.

Fufa, T. D., M. L. Harris, D. E. Watkins-Chow, D. Levy, D. U. Gorkin, D. E. Gildea, L. Song, A. Safi, G. E. Crawford, E. V. Sviderskaya, D. C. Bennett, A. S. Mccallion, S. K. Loftus, and W. J. Pavan. 2015. Genomic analysis reveals distinct mechanisms and functional classes of SOX10-regulated genes in melanocytes. Hum. Mol. Genet. 24:5433-5450. https://doi.org/10.1093/hmg/ddv267.

Gao, S., L. Yuan, Y. Wang, and C. Hua. 2017. Enhanced expression of TREM-1 in splenic cDCs in lupus prone mice and it was modulated by miRNA-150. Mol. Immunol. 81:127-134. https://doi.org/ 10.1016/j.molimm.2016.12.006.

Gasparin, G., M. Miyata, L. L. Coutinho, M. L. Martinez, R. L. Teodoro, J. Furlong, M. A. Machado, M. V. G. B. Silva, T. S. Sonstegard, and L. C. A. Regitano. 2007. Mapping of quantitative trait loci controlling tick [Riphicephalus (Boophilus) microplus] resistance on bovine chromosomes 5, 7 and 14. Anim. Genet. 38:453459. https://doi.org/10.1111/j.1365-2052.2007.01634.x.

Gasque, P., and M. C. Jaffar-Bandjee. 2015. The immunology and inflammatory responses of human melanocytes in infectious diseases. J. Infect. 71:413-421. https://doi.org/10.1016/j.jinf.2015.06.006.

Genua, M., S. Rutella, C. Correale, and S. Danese. 2014. The triggering receptor expressed on myeloid cells (TREM) in inflammatory bowel disease pathogenesis. J. Transl. Med. 12:293. https://doi .org/10.1186/s12967-014-0293-z.

Habier, D., R. L. Fernando, K. Kizilkaya, and D. J. Garrick. 2011 Extension of the Bayesian alphabet for genomic selection. BMC Bioinformatics 12:186. https://doi.org/10.1186/1471-2105-12-186.

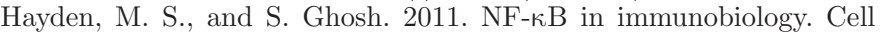
Res. 21:223-244. https://doi.org/10.1038/cr.2011.13.

Herrington, F. D., and R. Nibbs. 2016. Regulation of the adaptive immune response by the I $\kappa \mathrm{B}$ family protein Bcl-3. Cells 5:14. https:/ /doi.org/10.3390/cells5020014.

Hickey, J. M., B. P. Kinghorn, B. Tier, J. F. Wilson, N. Dunstan, and J. H. J. van der Werf. 2011. A combined long-range phasing and long haplotype imputation method to impute phase for SNP genotypes. Genet. Sel. Evol. 43:12. https://doi.org/10.1186/1297 $-9686-43-12$.

Hume, A. N., and M. C. Seabra. 2011. Melanosomes on the move: A model to understand organelle dynamics. Biochem. Soc. Trans. 39:1191-1196. https://doi.org/10.1042/BST0391191.

Ibelli, A. M. G., A. R. B. Ribeiro, R. Giglioti, L. C. A. Regitano, M. M. Alencar, A. C. S. Chagas, A. L. Paço, H. N. Oliveira, J. M. S. Duarte, and M. C. S. Oliveira. 2012. Resistance of cattle of various genetic groups to the tick Rhipicephalus microplus and the relationship with coat traits. Vet. Parasitol. 186:425-430. https://doi .org/10.1016/j.vetpar.2011.11.019.

Ju, X., P. A. Silveira, W.-H. Hsu, Z. Elgundi, R. Alingcastre, N. D. Verma, P. D. Fromm, J. L. Hsu, C. Bryant, Z. Li, F. Kupresanin, T.-H. Lo, C. Clarke, K. Lee, H. McGuire, B. Fazekas de St. Groth, S. R. Larsen, J. Gibson, K. F. Bradstock, G. J. Clark, and D. N. J. Hart. 2016. The analysis of CD83 expression on human immune cells identifies a unique CD83 ${ }^{+}$-activated T cell population. J. Immunol. 197:1600339. https://doi.org/10.4049/jimmunol.1600339. 
Kretschmer, B., K. Lüthje, A. H. Guse, S. Ehrlich, F. Koch-Nolte, F. Haag, B. Fleischer, and M. Breloer. 2007. CD83 modulates B cell function in vitro. Increased IL-10 and reduced Ig secretion by CD83Tg B cells. PLoS One 2. https://doi.org/10.1371/journal .pone.0000755.

Léger, E., G. Vourc'h, L. Vial, C. Chevillon, and K. D. McCoy. 2013. Changing distributions of ticks: Causes and consequences. Exp. Appl. Acarol. 59:219-244. https://doi.org/10.1007/s10493-012 $-9615-0$.

Lüthje, K., B. Kretschmer, B. Fleischer, and M. Breloer. 2008. CD83 regulates splenic B cell maturation and peripheral B cell homeostasis. Int. Immunol. 20:949-960. https://doi.org/10.1093/ intimm/dxn054.

Machado, M. A., A. L. S. Azevedo, R. L. Teodoro, M. A. Pires, M. G. C. D. Peixoto, C. de Freitas, M. C. A. Prata, J. Furlong, M. V. G. B. da Silva, S. E. F. Guimarães, L. C. A. Regitano, L. L. Coutinho, G. Gasparin, and R. S. Verneque. 2010. Genome wide scan for quantitative trait loci affecting tick resistance in cattle (Bos taurus $\times$ Bos indicus). BMC Genomics 11:280. https://doi.org/10.1186/ 1471-2164-11-280.

Maere, S., K. Heymans, and M. Kuiper. 2005. BiNGO: A Cytoscape plugin to assess overrepresentation of Gene Ontology categories in biological networks. Bioinformatics 21:3448-3449. https://doi.org/ 10.1093/bioinformatics/bti551.

Mailliard, R. B., S. M. Alber, H. Shen, and S. C. Watkins. 2005. IL-18-induced CD83+CCR7+ NK helper cells. J. Exp. Med. 202:941-953. https://doi.org/10.1084/jem.20050128.

Mapholi, N. O., A. Maiwashe, O. Matika, V. Riggio, S. C. Bishop, M. D. MacNeil, C. Banga, J. F. Taylor, and K. Dzama. 2016. Genome-wide association study of tick resistance in South African Nguni cattle. Ticks Tick Borne Dis. 7:487-497. https://doi.org/10 .1016/j.ttbdis.2016.02.005.

Martinez, M. L., M. A. Machado, C. S. Nascimento, M. V. G. B. Silva, R. L. Teodoro, J. Furlong, M. C. A. Prata, A. L. Campos, M. F. M. Guimarães, A. L. S. Azevedo, M. F. A. Pires, and R. S. Verneque. 2006. Association of BoLA-DRB3.2 alleles with tick (Boophilus microplus) resistance in cattle. Genet. Mol. Res. 5:513-524.

Misztal, I., S. Tsuruta, T. Strabel, B. Auvray, T. Druet, and D. H. Lee. 2002. BLUPF90 and related programs (BGF90). Pages 21-22 in Proc. 7th World Congr. Genet. Appl. to Livest. Prod. Vol. 28.

Molento, M. B., C. J. Veríssimo, A. T. Amarante, J. A. Van Wyk, A. C. S. Chagas, J. V. De Araújo, and F. A. Borges. 2013. Alternativas para o controle de nematoides gastrintestinais de pequenos ruminantes. Arq. Inst. Biol. (Sao Paulo) 80:253-263.

Morales, J., K. Villa, J. Gattis, W. Castro, K. Colon, J. Lubkowski, P. Sanabria, R. Hunter, and A. V. Washington. 2010. Soluble TLT-1 modulates platelet-endothelial cell interactions and actin polymerization. Blood Coagul. Fibrinolysis 21:229-236. https://doi.org/10 $.1097 /$ MBC.0b013e3283358116.

Pastural, E., F. Ersoy, N. Yalman, N. Wulffraat, E. Grillo, F. Ozkinay, I. Tezcan, G. Gediköglu, N. Philippe, A. Fischer, and G. de Saint Basile. 2000. Two genes are responsible for Griscelli syndrome at the same 15q21 locus. Genomics 63:299-306. https://doi.org/10 $.1006 /$ geno.1999.6081.

Porto Neto, L. R., N. N. Jonsson, M. J. D'Occhio, and W. Barendse. 2011. Molecular genetic approaches for identifying the basis of variation in resistance to tick infestation in cattle. Vet. Parasitol 180:165-172. https://doi.org/10.1016/j.vetpar.2011.05.048.

Prayaga, K. C., N. J. Corbet, D. J. Johnston, M. L. Wolcott, G. Fordyce, and H. M. Burrow. 2009. Genetics of adaptive traits in heifers and their relationship to growth, pubertal and carcass traits in two tropical beef cattle genotypes. Anim. Prod. Sci. 49:413-425. https://doi.org/10.1071/EA08247.

Sandelin, A., W. Alkema, P. Engström, W. W. Wasserman, and B. Lenhard. 2004. JASPAR: An open-access database for eukaryotic transcription factor binding profiles. Nucleic Acids Res. 32:D91D94. https://doi.org/10.1093/nar/gkh012.

Sargolzaei, M., J. P. Chesnais, and F. S. Schenkel. 2011. FImputeAn efficient imputation algorithm for dairy cattle populations. J. Anim. Sci. 89:333.
Schenk, M., A. Bouchon, F. Seibold, and C. Mueller. 2007. TREM1-expressing intestinal macrophages crucially amplify chronic inflammation in experimental colitis and inflammatory bowel diseases. J. Clin. Invest. 117. https://doi.org/10.1172/JCI30602.

Seillet, C., L. C. Rankin, J. R. Groom, L. A. Mielke, J. Tellier, M. Chopin, N. D. Huntington, G. T. Belz, and S. Carotta. 2014. Nfil3 is required for the development of all innate lymphoid cell subsets. J. Exp. Med. 211:1733-1740. https://doi.org/10.1084/jem 20140145 .

Seno, H., H. Miyoshi, S. L. Brown, M. J. Geske, M. Colonna, and T. S. Stappenbeck. 2009. Efficient colonic mucosal wound repair requires Trem2 signaling. Proc. Natl. Acad. Sci. USA 106:256-261. https://doi.org/10.1073/pnas.0803343106.

Sevillano, C. A., J. Vandenplas, J. W. M. Bastiaansen, and M. P. L. Calus. 2016. Empirical determination of breed-of-origin of alleles in three-breed cross pigs. Genet. Sel. Evol. 48:55. https://doi.org/ 10.1186/s12711-016-0234-9.

Shannon, P., A. Markiel, O. Ozier, N. S. Baliga, J. T. Wang, D. Ramage, N. Amin, B. Schwikowski, and T. Ideker. 2003. Cytoscape: A software environment for integrated models of biomolecular interaction networks. Genome Res. 13:2498-2504. https://doi.org/10 $.1101 / \mathrm{gr} .1239303$

Sharif, O., and S. Knapp. 2008. From expression to signaling: Roles of TREM-1 and TREM-2 in innate immunity and bacterial infection. Immunobiology 213:701-713. https://doi.org/10.1016/j .imbio.2008.07.008.

Shyma, K. P., J. P. Gupta, and V. Singh. 2015. Breeding strategies for tick resistance in tropical cattle : a sustainable approach for tick control. J. Parasit. Dis. 39:1-6. https://doi.org/10.1007/s12639 $-013-0294-5$.

Solé, X., E. Guinó, J. Valls, R. Iniesta, and V. Moreno. 2006. SNPStats: A web tool for the analysis of association studies. Bioinformatics 22:1928-1929. https://doi.org/10.1093/bioinformatics/btl268.

Souroullas, G. P., J. M. Salmon, F. Sablitzky, D. J. Curtis, and M. A. Goodell. 2009. Adult hematopoietic stem and progenitor cells require either Lyl1 or Scl for survival. Cell Stem Cell 4:180-186. https://doi.org/10.1016/j.stem.2009.01.001.

Tizard, I. R. 2008. Imunologia Veterinária: Uma Introdução. 9th ed. Elsevier, Rio de Janeiro, Brazil

Touzet, H., and J.-S. Varré. 2007. Efficient and accurate P-value computation for position weight matrices. Algorithms Mol. Biol. 2:15. https://doi.org/10.1186/1748-7188-2-15.

Turnbull, I. R., S. Gilfillan, M. Cella, T. Aoshi, M. Miller, L. Piccio, M. Hernandez, and M. Colonna. 2006. Cutting edge: TREM2 attenuates macrophage activation. J. Immunol. 177:3520-3524. https://doi.org/10.4049/jimmunol.177.6.3520.

Turner, L. B., B. E. Harrison, R. J. Bunch, L. R. P. Neto, Y. Li, and W. Barendse. 2010. A genome-wide association study of tick burden and milk composition in cattle. Anim. Prod. Sci. 50:235-245. https://doi.org/10.1071/AN09135.

Tze, L. E., K. Horikawa, H. Domaschenz, D. R. Howard, C. M. Roots, R. J. Rigby, D. A. Way, M. Ohmura-Hoshino, S. Ishido, C. E. Andoniou, M. A. Degli-Esposti, and C. C. Goodnow. 2011. CD83 increases MHC II and CD86 on dendritic cells by opposing IL10-driven MARCH1-mediated ubiquitination and degradation. J. Exp. Med. 208:149-165. https://doi.org/10.1084/jem.20092203.

Untalan, P. M., J. H. Pruett, and C. D. Steelman. 2007. Association of the bovine leukocyte antigen major histocompatibility complex class II DRB3*4401 allele with host resistance to the Lone Star tick, Amblyomma americanum. Vet. Parasitol. 145:190-195. https: //doi.org/10.1016/j.vetpar.2006.12.003.

van der Veer, A., V. van der Velden, M. Willemse, P. Hoogeveen, E. Petricoin, H. Beverloo, G. Escherich, M. Horstmann, R. Pieters, and M. den Boer. 2014. Interference with pre-B-cell receptor signaling offers a therapeutic option for TCF3-rearranged childhood acute lymphoblastic leukemia. Blood Cancer J. 4:e181. https://doi .org/10.1038/bcj.2014.5.

Vandenplas, J., M. P. L. Calus, C. A. Sevillano, J. J. Windig, and J. W. M. Bastiaansen. 2016. Assigning breed origin to alleles in 
crossbred animals. Genet. Sel. Evol. 481:401-413. https://doi.org/ 10.1186/S12711-016-0240-Y.

Verardo, L. L., F. F. Silva, M. S. Lopes, O. Madsen, J. W. M. Bastiaansen, E. F. Knol, M. Kelly, L. Varona, P. S. Lopes, and S. E. F. Guimarães. 2016. Revealing new candidate genes for reproductive traits in pigs : combining Bayesian GWAS and functional pathways. Genet. Sel. Evol. 48:9. https://doi.org/10.1186/s12711 -016-0189-x.

Viret, C., C. Lamare, M. Guiraud, N. Fazilleau, A. Bour, B. Malissen, A. Carrier, and S. Guerder. 2011a. Thymus-specific serine protease contributes to the diversification of the functional endogenous CD4 T cell receptor repertoire. J. Exp. Med. 208:3-11. https://doi .org/10.1084/jem.20100027.

Viret, C., S. Leung-Theung-Long, and L. Serre. 2011b. Thymus-specific serine protease controls autoreactive CD4 T cell development and autoimmune diabetes in mice. J. Clin. Invest. 121. https://doi .org/10.1172/JCI43314.

Walker, A. R. 2011. Eradication and control of livestock ticks: Biological, economic and social perspectives. Parasitology 138:945-959. https://doi.org/10.1017/S0031182011000709.
Wang, H., I. Misztal, I. Aguilar, A. Legarra, R. L. Fernando, Z. Vitezica, R. Okimoto, T. Wing, R. Hawken, and W. M. Muir. 2014. Genome-wide association mapping including phenotypes from relatives without genotypes in a single-step (ssGWAS) for 6-week body weight in broiler chickens. Front. Genet. 5:134. https://doi .org/10.3389/fgene.2014.00134.

Yamashiro, S., J. M. Wang, D. Yang, W. H. Gong, H. Kamohara, and T. Yoshimura. 2000. Expression of CCR6 and CD83 by cytokineactivated human neutrophils. Blood 96:3958-3963.

Zimin, A. V., A. L. Delcher, L. Florea, D. R. Kelley, M. C. Schatz, D. Puiu, F. Hanrahan, G. Pertea, C. P. Van Tassell, T. S. Sonstegard, G. Marçais, M. Roberts, P. Subramanian, J. A. Yorke, and S. L. Salzberg. 2009. A whole-genome assembly of the domestic cow, Bos taurus. Genome Biol. 10:R42. https://doi.org/10.1186/ gb-2009-10-4-r42 